\title{
Effect of Nitric Oxide Release from NOR-3 on Urea Synthesis, Viability and Oxygen Consumption of Rat Hepatocyte Cultures
}

\author{
R. CHIMENTI, G. MARTINO, S. MAZZULLA, S. SESTI \\ Department of Cell Biology, University of Calabria, Arcavacata di Rende, Italy
}

Received August 9, 2006

Accepted August 17, 2006

On-line available August 22, 2006

\begin{abstract}
Summary
As nitric oxide is considered a mediator of liver oxidative metabolism during sepsis, we studied the effects of exogenous nitric oxide, produced by NO-donor, $( \pm)$-(E)-4-ethyl-2-[(E)-hydroxyimino]-5-nitro-3-hexenamide (NOR-3), on cell viability, urea biosynthesis and oxygen consumption in rat hepatocyte cultures. Nitric oxide release from NOR-3 was studied using 4,5-diaminofluorescein diacetate. Urea levels were measured by the spectrophotometric method. Cell viability was determined by the MTT test and trypan blue exclusion test, whereas oxygen consumption was measured by a polarographic technique. After $2 \mathrm{~h}$ treatment, NOR-3 induced an increase in the levels of nitric oxide. After $2 \mathrm{~h}$ of treatment and $24 \mathrm{~h}$ after the end of the treatment with NOR-3, both cell viability and urea synthesis were significantly reduced in comparison to the controls for NOR-3 concentrations equal to or greater than $50 \mu \mathrm{M}$. A reduction in oxygen consumption was observed in hepatocytes after 40 min treatment with $100 \mu \mathrm{M}$ NOR-3, even if the cell viability was unchanged. Reduction of oxygen consumption is an early indicator of the metabolic alterations in hepatocytes exposed to nitric oxide. These findings suggest that nitric oxide accumulation acts on hepatocyte cultures inducing cell death and reduction of urea synthesis after 2 hours.
\end{abstract}

\section{Key words}

4,5 diamminofluorescein diacetate $\bullet$ Nitric oxide $\bullet$ Nitric oxide donor $\bullet$ Rat hepatocytes

\section{Introduction}

Nitric oxide (NO) is a free radical, present in conditions such as atmospheric pollution and cigarette smoke. In biological systems, NO has a short half-life in the order of seconds. NO has an oxidation intermediate state and is consequently capable both to oxidize and to reduce the chemical compounds with which it comes into contact. The biosynthesis mainly occurs through the transformation of L-arginine amino acid to citrulline.
This reaction requires the participation of NO synthase (NOS) enzyme. Recently, mitochondrial NOS (mtNOS) has been detected (Giulivi 2003). The endothelial (eNOS), the neuronal (nNOS) and the mitochondrial types of enzyme are constitutive. The inducible type (iNOS) is not modulated in its enzymatic activity by the intracellular $\mathrm{Ca}^{2+}$ concentration, as happens in the constitutive type (Taylor et al. 1998). The mechanisms by which NO can elicit changes in the hepatic metabolism can be considered from two aspects: 1) by exerting a 
direct effect on hepatic uptake, storage, detoxification and clearance mechanisms, and 2) by exerting an indirect effect, due to the induction of changes in hepatic vascular tone, which would ultimately affect these mechanisms. Currently, relatively little is known about the direct mechanisms. This offers a very exciting and progressively expanding area of research (Alexander 1998).

The present study was conducted to assess the effects of exogenous NO on viability, on urea biosynthesis and oxygen consumption in cultured rat hepatocytes by spectrofluorimetric and spectrophotometric techniques. Thus, the cell cultures were treated with the NO-donor, NOR-3, releasing NO spontaneously at physiological $\mathrm{pH}$. NOR-3 releases NO with a half-life time of $105 \mathrm{~min}$ which is too long for NO to be metabolized in a short time. Consequently, free NO will accumulate in the cell cultures inducing cell death (Yamamoto et al. 2000).

\section{Methods}

Unless otherwise specified, all chemicals were obtained from Sigma (St. Louis, MO, USA). Hepatocytes were isolated from male Wistar rats (180-200 g, fed a standard diet), by a modification of the method of Seglen (1976). All procedures on the animals were performed according to the European Convention for the Protection of Vertebrate Animals used for Experimental and other Scientific Purposes (Council of Europe No 123, Strasbourg 1985). Rats were anesthetized with diethylether, the pre-perfusion of the liver in situ was performed at a rate of 20-30 ml/min with $\mathrm{Ca}^{2+}$-free Hanks balanced salt solution. The liver was then completely excized and digestion was carried out by adding $0.05 \%$ $(\mathrm{w} / \mathrm{v})$ collagenase (type IV) in Hanks balanced salt solution supplemented with $\mathrm{CaCl}_{2}(0.0186 \mathrm{~g} / \mathrm{l})$ at a flux rate of $40 \mathrm{ml} / \mathrm{min}$. At this point, the liver was transferred on to a plate containing $100 \mathrm{ml}$ of RPMI 1640 medium supplemented with $200 \mathrm{mM}$ L-glutamine, $20 \mathrm{ml} / 1$ essential amino acid solution and $10 \mathrm{ml} / 1$ non-essential amino acid solution, $1 \%$ antibiotic antimycotic stabilized solution (incomplete medium). The cells were dispersed by gentle disruption with a stainless steel comb. After filtration through a $200 \mu \mathrm{m}$ Nytal mesh, parenchymal cells (hepatocytes) were separated from nonparenchymal cells (endothelial cells, Kupffer cells and stellate cells) by centrifugation at $50 \times \mathrm{g}$ in an Eppendorf Centrifuge $5810 \mathrm{R}$ at $4{ }^{\circ} \mathrm{C}$ for $2 \mathrm{~min}$ and then washed twice in a washing buffer (Blomhoff and Berg 1990). The cells were then resuspended in the same medium and filtered through a $63 \mu \mathrm{m}$ Nytal mesh. The viability of the cells was higher than $80 \%$, as estimated by trypan blue dye exclusion test (Kaltenbach et al. 1958). After cell counting the cells were diluted at a concentration of $5 \mathrm{x}$ $10^{5} \mathrm{cells} / \mathrm{ml}$ with incomplete medium supplemented with $2 \%$ fetal calf serum, $0.1 \mathrm{U} / \mathrm{ml}$ insulin and $10^{-6} \mathrm{M}$ dexamethasone (complete medium). The hepatocytes were then plated in 24 well-plates coated with rat tail collagen at the final cell density of $2.5 \times 10^{5}$ cells per well and incubated at $37{ }^{\circ} \mathrm{C}$ in an humidified atmosphere of 5 $\% \mathrm{CO}_{2}$ and $95 \%$ air. After $6 \mathrm{~h}$ incubation, the medium was replaced with an incomplete medium to remove the dead cells.

To verify the isolation method efficacy, the acid phosphatase activity per mg of proteins was evaluated. According to literary data, the specific activity of acid phosphatase in nonparenchymal cells is 1.7 fold greater than that in parenchymal cells (Munthe Kaas et al. 1976).

After $24 \mathrm{~h}$ in culture, the hepatocytes were exposed to NOR-3 $(10,50,100,150 \mu \mathrm{M}$ final concentrations). DAF-2DA (Alexis Biochemicals, Lausen, Switzerland) was dissolved in DMSO $(1 \mathrm{mg} /$ $0.45 \mathrm{ml}$ ) and diluted to $10 \mu \mathrm{M}$ in a phosphate buffer $(0.1 \mathrm{M}, \mathrm{pH}$ 7.4). Then the cells were incubated in a phosphate buffer containing $10 \mu \mathrm{M}$ DAF-2DA and NOR-3 (10, 50, 100, $150 \mu \mathrm{M}$ final concentrations).

After $2 \mathrm{~h}$ incubation in this reaction mixture, the fluorescence from the reaction of DAF-2DA with NO released from NOR-3 was measured with Perkin-Elmer MPF-44B spectrofluorimeter calibrated for excitation at $495 \mathrm{~nm}$ and emission at $515 \mathrm{~nm}$. Results were expressed as a percentage of the fluorescence of the samples in comparison to the control.

To determine the effects of NO on urea production, cells were treated with NOR-3 $(10,50,100$, $150 \mu \mathrm{M}$ final concentrations). To the same medium $1 \mathrm{mM} \mathrm{NH}_{4} \mathrm{Cl}$ was added. After $2 \mathrm{~h}$ incubation and $24 \mathrm{~h}$ after the end of NOR-3 treatment, urea levels in the medium were measured by the spectrophotometric method using Urea Color 2 Kit (Sclavo Diagnostics, Siena, Italia) measuring absorbance at $600 \mathrm{~nm}$. Determinations on blank samples with the same $\mathrm{NH}_{4} \mathrm{Cl}$ final concentration were used as reference. Urea synthesis was calculated as ng urea per cell per hour.

Cell viability was determined by MTT test (Mosmann 1983) and confirmed by Trypan blue exclusion test (Kaltenbach et al. 1958). MTT $(5 \mathrm{mg} / \mathrm{ml})$ 


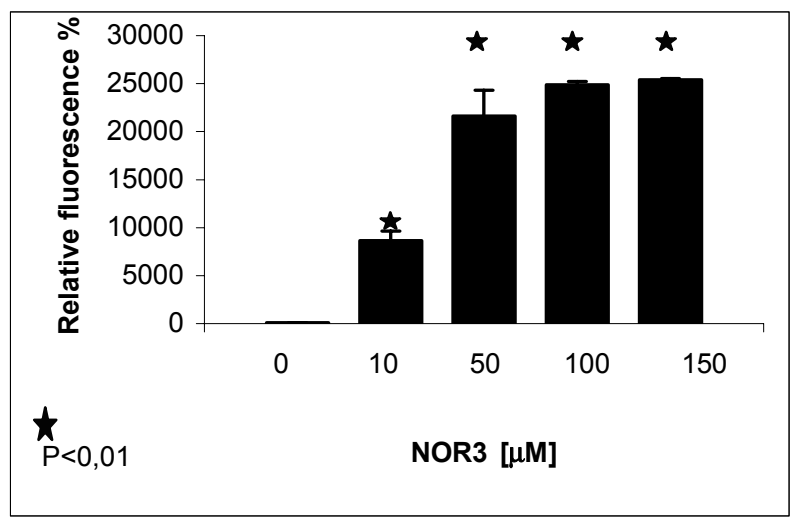

Fig. 1. Determination of NO release after treatment of hepatocytes with NOR-3. The NO release after treatment of hepatocytes with NOR-3 was spectrofluorometrically determined. Fluorescence intensity was measured after $2 \mathrm{~h}$ incubation with $10 \mu \mathrm{M}$ DAF-2DA in basal conditions and in the presence of NOR-3 $(10,50,100$ and $150 \mu \mathrm{M})$. The excitation wavelength was $495 \mathrm{~nm}$ and the emission wavelength was $515 \mathrm{~nm}$. Values, expressed as a percentage of control values, are means \pm S.E.M. of four independent experiments. $* \mathrm{P}<0.01$ compared with control.

was dissolved in RPMI-1640 without phenol red. The solution is filtered through a $0.2 \mu \mathrm{m}$ filter and stored at 2-8 ${ }^{\circ} \mathrm{C}$ for frequent use. To determine the effects of NOR-3 on cell viability, cells were treated with NOR-3 $(10,50,100,150 \mu \mathrm{M}$ final concentrations) for a $2 \mathrm{~h}$ period. After that cells were used either immediately or after an additional $24 \mathrm{~h}$ incubation in an incomplete medium. For the determination of cell viability, the medium was discarded and the MTT solution was added and incubated for $3 \mathrm{~h}$. At the end of the incubation period the MTT solution was removed and the cells and dye crystals were dissolved by adding dimethylsulfoxide (DMSO). Absorbance was measured at $570 \mathrm{~nm}$ in a Shimadzu UV-2100 spectrophotometer and the results were expressed as a percentage of the absorbance of the samples in comparison to the control.

The oxygen consumption in NO-exposed hepatocytes was measured by the polarographic technique using an oxygen-sensitive microelectrode (Estabrook 1967). A total of $5 \times 10^{6}$ hepatic parenchymal cells $(250000 / \mathrm{ml})$ were preincubated in $20 \mathrm{ml}$ Hanks solution for $15 \mathrm{~min}$ at $37^{\circ} \mathrm{C}$. NOR-3, as NO-donor, was then added to the cell preparation at different concentrations $(10 \mu \mathrm{M}$ and $100 \mu \mathrm{M})$. The solution containing the hepatocytes was first saturated with oxygen by stirring and then the oxygen consumption was measured during $40 \mathrm{~min}$.

At least four independent determinations of each parameter were compared to the controls using Student's T-test that is useful for comparing two groups of data in the same experiment. Differences were considered significant when was $\mathrm{p}<0.05$.

\section{Results}

\section{NO release from NOR-3}

The amounts of released NO were measured by using DAF-2DA, which specifically reacts with the oxidized form of $\mathrm{NO}$, producing the fluorescent derivative triazolofluorescein (Kojima et al. 1998). NO determination was performed after $2 \mathrm{~h}$ incubation in the presence of NOR-3 $(10,50,100$ and $150 \mu \mathrm{M})$. As shown in Figure 1, the treatment with NOR-3, in all the studied concentrations produced a significant NO increase compared to the control.

\section{Effect of NOR-3 on urea production}

To evaluate urea synthesis after NOR-3 treatment, the hepatocytes were treated with $1 \mathrm{mM}$ $\mathrm{NH}_{4} \mathrm{Cl}$ for $2 \mathrm{~h}$. Urea production, expressed as $\mathrm{ng} / \mathrm{h} / \mathrm{cell}$, was observed after $2 \mathrm{~h}$ incubation in the presence of NOR-3 $(10,50,100$ and $150 \mu \mathrm{M})$ and $24 \mathrm{~h}$ after the end of NOR-3 treatment. After $2 \mathrm{~h}$ treatment a significant increase of urea synthesis was observed only with $10 \mu \mathrm{M}$ NOR-3; a significant decrease of urea synthesis was observed with 100 and $150 \mu \mathrm{M}$ NOR-3 (Fig. 2A). A significant decrease of urea synthesis was also observed $24 \mathrm{~h}$ after the end of the treatment with NOR-3 (50, 100 and $150 \mu \mathrm{M})$ (Fig. 2B).

\section{Effect of NOR-3 on cell viability}

To assess the possible toxic effects of $\mathrm{NO}$ on cell viability, the hepatocytes were exposed to NOR-3 (10, 50,100 and $150 \mu \mathrm{M}$ ) for an incubation time of 2 hours. As shown in Fig. 3A, NOR-3 induces a significant decrease in cell viability at concentrations 50, 100 and $150 \mu \mathrm{M}$. Furthermore, $24 \mathrm{~h}$ after the end of the treatment, the decrease in cell viability was more marked (Fig. 3B). Cell viability data were validated by the Trypan blue exclusion test (data not shown).

\section{Effect of NOR-3 on oxygen consumption}

The oxygen consumption was measured in hepatocytes treated with NOR-3 $(0.01$ and $0.1 \mathrm{mM})$ during 40 min treatment. As shown in Figure 4, NOR-3 $(0.1 \mathrm{mM})$ significantly decreased oxygen consumption in comparison to control hepatocytes during 40 min treatment. The cell viability was not significantly different from the control value (Fig. 5). 

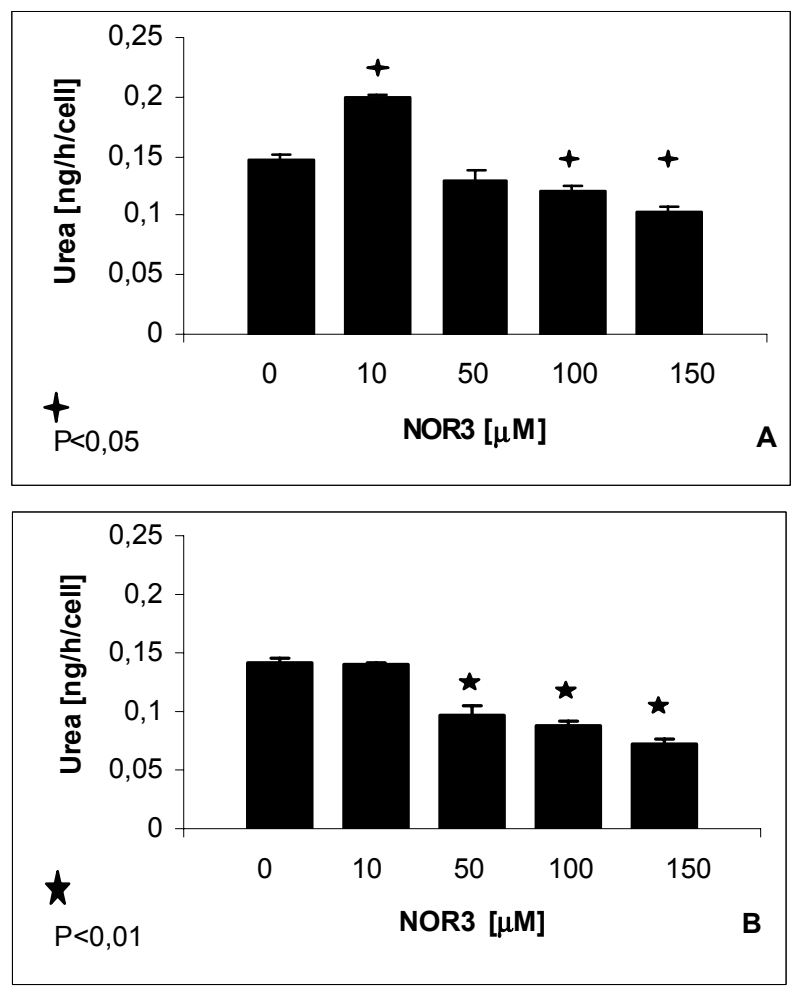

Fig. 2. Determination of urea production after treatment of hepatocytes with NOR-3. The urea production after treatment of hepatocytes with NOR-3 was spectrophotometrically determined at $600 \mathrm{~nm}$ after $2 \mathrm{~h}$ incubation with $1 \mathrm{mM} \mathrm{NH} \mathrm{NH}_{4} \mathrm{Cl}$ basal conditions and in the presence of NOR-3 (10, 50, 100 and 150 $\mu \mathrm{M})$. Urea production determined immediately after $(\mathbf{A})$ and after an additional $24 \mathrm{~h}$ incubation period in incomplete medium (B). Values, expressed as ng urea per cell per hour, are means \pm S.E.M. of four independent experiments. $\quad \mathrm{P}<0.05$ compared with control. $* \mathrm{P}<0.01$ compared with control.

\section{Discussion}

It is well known that NOR-3 treatment induces cell toxicity on PC12 cells, which is strongly dependent on the duration of NO exposure. Indeed, the cell toxicity of NOR-3 is lost when the drug is removed by replacing the medium within the first hour. As PC12 cells are exposed to NOR-3 for more than $2 \mathrm{~h}$, the toxic effect of NOR-3 became significant (Yamamoto et al. 2000). Our results indicate that hepatocyte exposure to NOR-3 (10 $\mu \mathrm{M})$ does not induce cell damage and we observed an increase of urea biosynthesis after $2 \mathrm{~h}$ treatment. When NO is synthesized from arginine, by the NO synthase (NOS) reaction, citrulline, an intermediate product of the urea cycle, is formed. Thus, the urea cycle is bypassed by the NOS reaction (Tabuchi et al. 2000). We hypothesize that exogenous NO at low concentrations exerts a negative feedback on NO synthase (NOS) activity, the urea cycle is not bypassed and this process induces an increase of urea levels. NOR-3 (100 and $150 \mu \mathrm{M})$
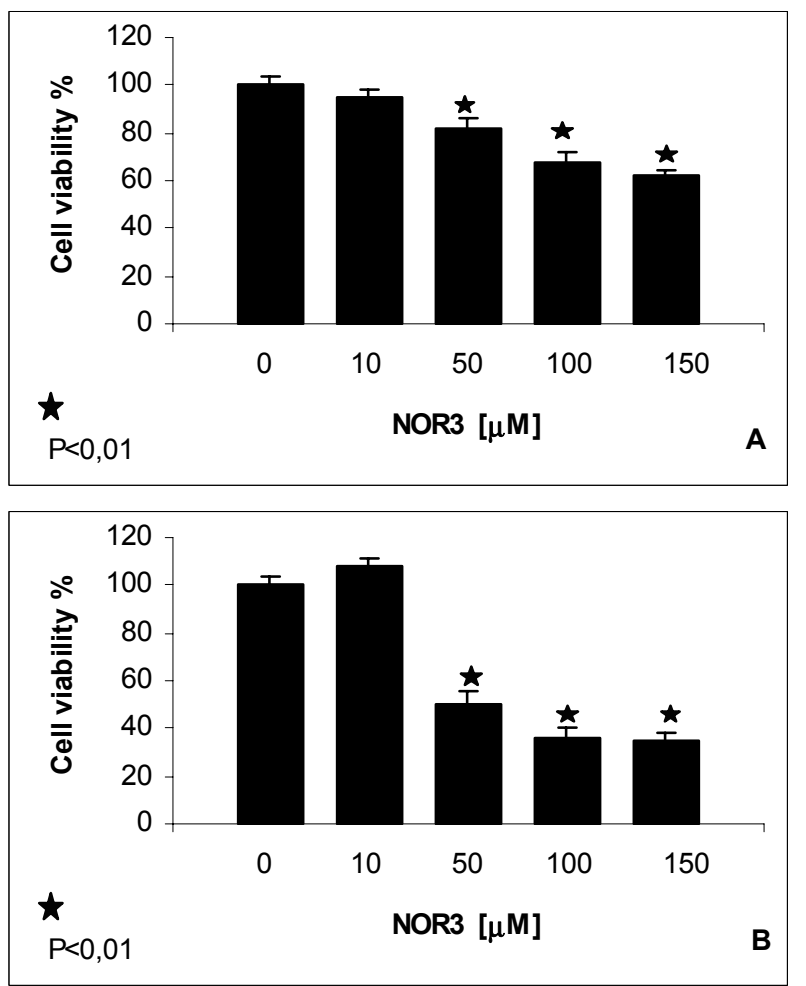

Fig. 3. Determination of cell viability in hepatocytes treated with NOR-3. The cell viability was spectrophotometrically determined at $570 \mathrm{~nm}$ by MTT assay in hepatocytes incubated in basal conditions and in presence of NOR-3 (10, 50, 100 and $150 \mu \mathrm{M})$ for $2 \mathrm{~h}$ period. Cell viability determined immediately after $(\mathbf{A})$ and after an additional $24 \mathrm{~h}$ incubation period in incomplete medium (B). Results are expressed as a percentage of control. Values are means \pm S.E.M. of four independent experiments. $* \mathrm{P}<0.01$ compared with control.

treatment for $2 \mathrm{~h}$ induces cell toxicity with a reduction in cell viability and urea biosynthesis. Cell toxicity also remains evident $24 \mathrm{~h}$ after the end of the treatment. Indeed, NOR-3 releases too much NO in order to be metabolized in a short time. Free NO will accumulate to induce cell death. This confirms that cell toxicity induced by NO depends on both the NO production rate and the NO exposure duration. We studied oxygen consumption during NOR-3 treatment and we observed a reduction in oxygen consumption probably due to an increase of $\mathrm{NO}$ levels. In fact, it has been demonstrated that NO can act by inhibiting the mitochondrial respiration in a reversible way competing with molecular oxygen. Therefore, NO causes a condition similar to "metabolic hypoxia" in which oxygen is present but it can not be used for mitochondrial respiration (Mateo et al. 2003). Marked increases of NO levels can reduce cell viability and urea biosynthesis. Indeed, low NO concentrations are quickly metabolized from the biological systems (Yamamoto et al. 2000). This is a confirmation of the double phase 


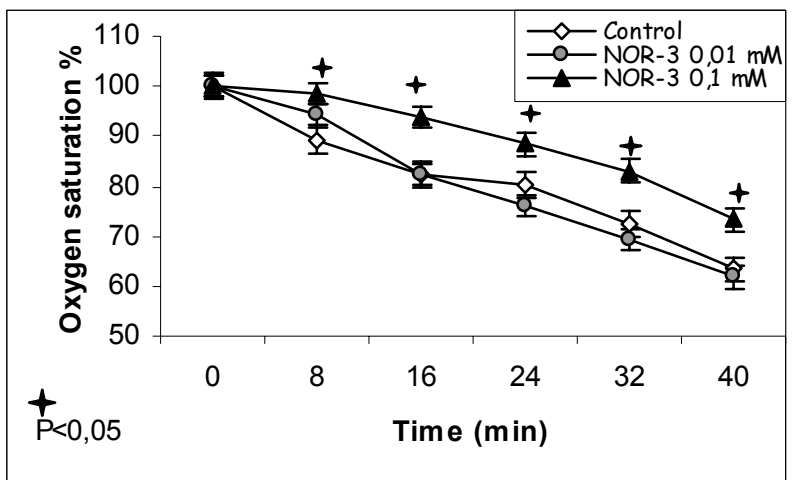

Fig. 4. Determination of oxygen consumption in hepatocytes treated with NOR-3. Oxygen consumption was polarographically measured during 40 min incubation of hepatocytes under basal conditions and in the presence of NOR-3 (0.01 and $0.1 \mathrm{mM})$. Results are expressed as a percentage of control. Values are means \pm S.E.M. of four independent experiments. $\mathrm{P}<0.05$ compared with control.

(cytoprotective or cytotoxic), dose-dependent, NO effect. The reduction in oxygen consumption due to the increase of the NO levels could be an indicator of the metabolic alterations of the isolated hepatocytes exposed to NO. NO may play an important role in the systemic response to infections in general; hepatic dysfunction after sepsis is a frequent event that is characterized by loss of synthetic function, hepatocellular necrosis and release of inflammatory mediators such as NO (Nadler et al. 2001).

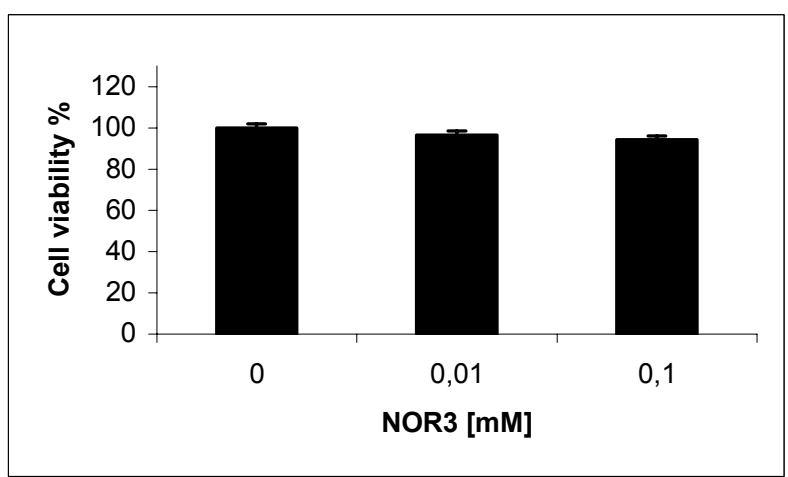

Fig. 5. Determination of cell viability in hepatocytes treated with NOR-3. The cell viability was spectrophotometrically determined at $570 \mathrm{~nm}$ by MTT assay in hepatocytes incubated in basal conditions and in the presence of NOR-3 $(0.01$ and $0.1 \mathrm{mM})$ for $40 \mathrm{~min}$ period. Results are expressed as a percentage of control. Values are means \pm S.E.M. (bars) of four independent experiments.

NO scavenger NOX and L-NAME, a known inhibitor of NOS, may consequently have important implications for the treatment of septic shock and other inflammatory conditions associated with sustained production of NO.

\section{Acknowledgements}

The research is supported by Italian Ministry of University and Scientific Research funding.

\section{References}

ALEXANDER B: The role of nitric oxide in hepatic metabolism. Nutrition 14: 376-390, 1998.

BLOMHOFF R, BERG T: Isolation and cultivation of rat liver stellate cells. Methods Enzymol 190: 58-71, 1990.

ESTABROOK RW: Mitochondrial respiratory control and the polarographic measurement of ADP: O ratios. Methods Enzymol 10: 41-47, 1967.

GIULIVI C: Characterization and function of mitochondrial nitric oxide synthase. Free Radic Biol Med 34: 397-408, 2003.

KALTENBACH JP, KALTENBACH MH, LYONS WB: Nigrosin as a dye for differentiating live and dead ascites cells. Exp Cell Res 15: 112-117, 1958.

KOJIMA H, SAKURAI K, KIKUCHI K, KAWAHARA S, KIRINO Y, NAGOSHI H, HIRATA Y, NAGANO T: Development of a fluorescent indicator for nitric oxide based on the fluorescein chromofore. Chem Pharm Bull 46: 373-375, 1998.

MATEO J, GARCIA-LECEA M, CADENAS S, HERNANDEZ C, MONCADA S: Regulation of hypoxia-inducible factor-1alpha by nitric oxide through mitochondria-dependent and independent pathways. Biochem J 376: 537 544, 2003.

MOSMANN TR: Rapid colorimetric assay for cellular growth and survival: application to proliferation and cytotoxicity assay. J Immunol Methods 65: 55-63, 1983.

MUNTHE KAAS AC, BERG T, SELIELID R: Distribution of lysosomal enzymes in different types of rat liver cells. Exp Cell Res 99: 146-154, 1976.

NADLER EP, DICKINSON EC, BEER-STOLZ D, ALBER SM, WATKINS SC, PRATT DW, FORD HR: Scavenging nitric oxide reduces hepatocellular injury after endotoxin challenge. Am J Physiol 281: G173-G181, 2001. 
SEGLEN PO: Preparation of isolated rat liver cells. Methods Cell Biol 13: 29-83, 1976.

TABUCHI S, GOTOH T, MIYANAKA K, TOMITA K, MORI M: Regulation of genes for inducible nitric oxide synthase and urea cycle enzymes in rat liver in endotoxin shock. Biochem Biophys Res Commun 268: 221-224, 2000.

TAYLOR BS, ALARCON LH, BILLIAR TR: Inducible nitric oxide synthase in the liver: regulation and function. Biochemistry (Moscow) 63: 766-781, 1998.

YAMAMOTO T, YUYAMA K, NAKAMURA K, KATO T, YAMAMOTO H: Kinetic characterization of the nitric oxide toxicity for PC12 cells: effect of half-life time of NO release. Eur J Pharmacol 397: 25-33, 2000.

\section{Corresponding author}

G. Martino, Via Pietro Bucci, University of Calabria, Arcavacata di Rende 87030, Italy. Fax: +39 984/492911. E-mail: martino@unical.it 